\title{
A Confocal Laser Microscopic Study of Enkephalin-Immunoreactive Appositions onto Physiologically Identified Neurons in the Rostral Ventromedial Medulla
}

\author{
P. Mason, ${ }^{1, a}$ S. A. Back, ${ }^{1}$ and H. L. Fields ${ }^{1,2}$ \\ Departments of 'Neurology and ${ }^{2}$ Physiology, and the William B. Keck Center for Integrative Neuroscience, University of \\ California at San Francisco, San Francisco, California 94143
}

Neurons in the rostral ventromedial medulla (RVM) are important in the opioid modulation of dorsal horn nociceptive transmission. Systemically administered morphine inhibits one class of RVM cells, the on-cells; excites a second class of RVM cells, the off-cells; and has no effect on a third class, neutral cells. In contrast, iontophoretic application of morphine inhibits on-cells but does not alter the activity of either off- or neutral cells. The present study addresses whether the differential sensitivity to exogenous opioids is correlated with a differential termination pattern onto the three classes of RVM neurons by afferents containing endogenous opioids.

Intracellular recordings were made from RVM neurons in rats under light halothane anesthesia. Physiologically characterized neurons were injected with Neurobiotin and then subsequently visualized with a Texas red fluorophore. Thick $(50 \mu \mathrm{m})$ sections containing labeled RVM cells were processed for enkephalin immunoreactivity (ENK-IR) using an FITC fluorophore and then optically sectioned at $1.5 \mu \mathrm{m}$ intervals using a dual-channel confocal laser scanning microscope. ENK-IR appositions were found on the somata and dendrites of all on-cells. Although ENK-IR varicositles were also apparently apposed to off- and neutral cells, the density of such appositions was significantly less than the density of ENK-IR appositions onto on-cells. The greater overall density of ENK-IR appositions onto on-cells was apparently due to a concentration of appositions on the soma and proximal dendrites of these neurons.

These results support a model of RVM function in which endogenous opioid peptides produce an antinociceptive action by a direct inhibitory action on on-cells that facilitate nociceptive transmission. This on-cell inhibition may produce an additional antinociceptive effect by removing a pos-

\footnotetext{
Received Feb. 6, 1992; revised May 21, 1992; accepted May 26, 1992.

This research was supported by U.S. Public Health Service Grant NS-21445 (H.L.F.) and by the Bristol-Myers Squibb Foundation. P.M. was supported by U.S. Public Health Service Grant NS-07265 and by a presidential fellowship from the University of California Board of Regents. We thank Drs. Y. N. Jan and L. Y. Jan for the use of their confocal microscope and Larry Ackerman for assistance in its use. The authors also thank Sonja Potrebic for her assistance and comments

Drs. Allan Basbaum and Peter Ralston for the use of equipment, Dr. Roger Nicol for his comments on the manuscript, and Mechelle Williams for histological support.

Correspondence should be addressed to Dr. Peggy Mason, Department of Neurology, M-794, University of California-San Francisco, San Francisco, CA 94143 0114 .

a Present address: Department of Pharmacological and Physiological Sciences, University of Chicago, Chicago, IL 60637.

Copyright (C) 1992 Society for Neuroscience $0270-6474 / 92 / 124023-14 \$ 05.00 / 0$
}

sible on-cell inhibition of off-cells, which are thought to inhibit nociceptive transmission.

Opioids, the most powerful pain-relieving agents known (Fields, 1987; Jaffe and Martin, 1990), produce their analgesic effect through actions at CNS sites that include the midbrain periaqueductal gray (PAG) and the rostral ventromedial medulla (RVM). The RVM, a region that includes nucleus raphe magnus and the adjacent ventromedial reticular formation (Basbaum and Fields, 1984; Mason et al., 1990), is of particular interest because it contains neurons that project to spinal and trigeminal dorsal horn laminae that are implicated in pain transmission.

Endogenous opioid peptides were originally purified using a bioassay for opioid receptor activity and were subsequently defined as peptides containing the sequence Tyr-Gly-Gly-Phe-[Leu or Met] (Hughes, 1975; Akil et al., 1984; Simon, 1991). The three families of endogenous opioid peptides include peptides derived from proopiomelanocortin, prodynorphin, and proenkephalin. The contribution of endogenous opioid peptides to the modulation of nociceptive transmission is best understood for those peptides that are derived from proenkephalin.

The enkephalins, leu-enkephalin, met-enkephalin, and several C-terminal extended forms of enkephalin, have a widespread distribution in the CNS (Murakami et al., 1987; Mansour et al., 1988) and are concentrated in pain modulatory regions of the brainstem including the RVM (Khachaturian et al., 1983; Williams and Dockray, 1983; Guthrie and Basbaum, 1984). Despite extensive literature on the enkephalinergic modulation of pain transmission (Azami et al., 1982; Akil et al., 1984; Dickenson and Le Bars, 1987; Randich et al., 1987; Basbaum and Besson, 1991; Vaught, 1991), the mechanisms by which endogenous opioids produce antinociception in vivo remain obscure.

Microinjections of metabolically stable synthetic enkephalin analogs into the RVM produce antinociceptive effects both on nociceptive reflexes and on nociceptive dorsal horn cells (Gebhart, 1982; Jensen and Yaksh, 1986). Furthermore, microinjection of SCH32615, a specific inhibitor of endopeptidase 24.11, into the RVM produces a dose-dependent antinociception that is reversed by systemic naloxone (Al-Rodhan et al., 1990), evidence that endogenous enkephalins are released within the RVM where they evoke an antinociceptive effect. Clearly, a further understanding of how endogenous opioids produce antinociception requires knowledge of their actions upon the neurons of the RVM.

The RVM contains at least three physiologically defined classes of cells (Fields et al., 1983a, 1991). One class of RVM cells, 
the off-cells, is excited by morphine administration (Fields et al., 1983b; Cheng et al., 1986; Rosenfeld et al., 1990) and is hypothesized to have a net inhibitory effect on nociceptive transmission at the level of the dorsal horn (Fields et al., 1991). Oncells, in contrast, are inhibited by systemic morphine and are activated during periods of increased responsiveness to noxious stimuli, evidence that these neurons have a net excitatory effect on dorsal horn nociceptive transmission (Heinricher et al., 1989; Bederson et al., 1990). A third class of RVM neurons, neutral cells, do not respond to noxious peripheral stimulation or morphine; their function, with regard to nociceptive modulation, is unclear. About 30\% of on-, off-, and neutral cell populations can be antidromically driven by dorsolateral funiculus stimulation, evidence that members of each class project to the spinal cord (Vanegas et al., 1984).

The cellular mechanisms by which RVM neurons respond to exogenous opioids are of obvious interest and importance in understanding the endogenous opioid modulation of nociceptive transmission. Iontophoretically applied morphine inhibits RVM on-cells (Heinricher et al., 1992). In contrast, although systemic, midbrain, or RVM microinjection of morphine excites off-cells, iontophoretic morphine has no effect on off-cell discharge, evidence that opioid excitation of off-cells is indirect. Morphine, administered by iontophoresis, microinjection into the midbrain, or systemically, has no effect on neutral cells.

If endogenous enkephalins act within the RVM to produce analgesia by a mechanism analogous to morphine, one would predict that opioid afferents and opioid receptors would be differentially distributed onto RVM on-, off-, and neutral cells. The present study investigates the former possibility by determining the relative distribution of enkephalin-immunoreactive (ENK-IR) swellings onto physiologically characterized RVM neurons. Past studies using immunocytochemical techniques to analyze circuitry in other CNS regions have employed either an electron microscopic approach that is very time consuming or a light microscopic examination of thick sections, a method that has relatively low resolution, especially in the $\mathrm{z}$ - (depth) axis. By using the confocal scanning laser microscope (CSLM), we have attempted in this study to address both of these limitations. The CSLM permits rapid optical sectioning of thick sections, which reduces the time consumed by labor-intensive anatomical sectioning methods. Additionally, the CSLM has a resolution limit of $0.2 \mu \mathrm{m}$ in the $\mathrm{x}-\mathrm{y}$-plane and $0.65 \mu \mathrm{m}$ in the $\mathrm{z}$-plane (Pawley, 1990). The latter represents a significant increase over the resolution of conventional fluorescence or transmitted light microscopy. In this study, the CSLM was used to map the distribution of appositions between ENK-IR profiles and physiologically identified RVM cells, intracellularly stained with Neurobiotin.

\section{Materials and Methods}

Male Sprague-Dawley rats (240-325 gm) were used in all experiments $(N=13)$. Animals were initially anesthetized with sodium pentobarbital $(30 \mathrm{mg} / \mathrm{kg}$, i.p.) and then maintained on $0.5-1.5 \%$ halothane in oxygen.

The methods for physiological recording have been described previously (Mason and Fields, 1989) and will only be briefly detailed here. Glass micropipettes were filled with $2.0 \%$ Neurobiotin (Vector) in 0.1 $\mathrm{M}$ Tris buffer ( $\mathrm{pH} 7.4$ ) and $0.15 \mathrm{M}$ potassium chloride. All micropipettes were pulled to a final tip resistance of 40-90 M . Recordings were made from neurons in the pontomedullary raphe nuclei and adjacent medial reticular formation. All neurons were characterized by their intracellular responses during a flexion withdrawal reflex evoked by noxious pinch or heat. Pressure from toothed forceps that was judged painful by application to a fold of the investigator's hand skin was used as a noxious pinch. Feedback-controlled noxious thermal stimuli were applied to the tails of rats as described previously (Fields et al., 1983a; Mason et al., 1990).

Following electrophysiological characterization as described above, neurons that were stably impaled were injected intracellularly with Neurobiotin using a constant depolarizing current of 1-5 $\mathrm{nA}$ for at least 4 min (adapted from Horikawa and Armstrong, 1988). In cases where the injected neuron was still impaled after the original $4 \mathrm{~min}$, depolarizing current was injected for another 2-10 min.

After the recording session, animals were killed by pentobarbital overdose and perfused with saline followed by a fixative containing $4.0 \%$ paraformaldehyde and $0.2 \%$ glutaraldehyde with $7 \%$ sucrose in $0.1 \mathrm{M}$ phosphate-buffered saline (PBS). The tissue was blocked coronally and then immersed in $30 \%$ sucrose in $0.1 \mathrm{M}$ PBS overnight. Serial transverse sections, $50 \mu \mathrm{m}$ thick, were then cut on a freezing microtome.

All sections were reacted in $0.4 \%$ avidin conjugated to Texas red (Vector Labs) and $0.5 \%$ Triton X-100 in $0.1 \mathrm{M}$ PBS for $4 \mathrm{hr}$ at $4^{\circ} \mathrm{C}$. After rinsing the sections in PBS, the sections were examined under a fluorescent microscope. Sections containing labeled neurons, including adjacent sections both rostral and caudal to the soma, were then further processed for enkephalin immunocytochemistry.

The primary antibody employed in the present study was raised against leu-enkephalin (Sera Labs). Since this monoclonal antibody was raised against the $\mathrm{NH}_{2}$ terminal of the opioid peptide, it also recognizes metenkephalin and has substantial cross-reactivity to several C-terminalextended enkephalin peptides (Cuello et al., 1984). IIowever, the antibody has no detectable cross-reactivity with $\beta$-endorphin or dynorphin $_{1-13}$.

The protocol used for enkephalin immunocytochemistry involved is briefly described below. Sections were incubated in $0.1 \mathrm{M}$ lysine in PBS containing $0.1 \%$ Triton X-100 and $2 \%$ normal horse serum (NHS) for $2 \mathrm{hr}$ at $4^{\circ} \mathrm{C}$. Sections were then transferred, without a wash, to a mouse monoclonal antibody directed against enkephalin (Sera Labs) at a 1:40 dilution in buffer A (PBS containing 2\% NHS and 0.1\% Triton X-100). Sections remained in the primary antibody for $18-72 \mathrm{hr}$ at $2-4^{\circ} \mathrm{C}$. After washes in ice-cold buffers, the sections were transferred to horse antimouse IgG conjugated to fluorescein (1:250 in buffer A) for $6 \mathrm{hr}$ at $2-$ $4^{\circ} \mathrm{C}$. After a final wash in ice-cold buffers, sections were then mounted on unsubbed slides and coverslipped with $p$-phenylethylenediamine.

Labeled neurons were examined under a $63 \times$ oil immersion objective using a confocal microscope (Bio-Rad MRC-600). Images were acquired in the dual-channel $(505-540 \mathrm{~nm}, 589-621 \mathrm{~nm})$ mode at $1.5 \mu \mathrm{m}$ intervals throughout the soma and dendrites. In the dual-channel mode, Texas red and FITC images are collected at each $z$-axis position, without moving the stage. At each z-axis position, the laser beam scans the section three to five times; the average brightness at each pixel location is then calculated and recorded. A zoom of 1-2 was employed in all cases. In the case of a few dendrites, the tissue was optically sectioned at $3 \mu \mathrm{m}$ intervals.

The detection aperture of a CSLM determines the depth of field that is imaged at each point. The depth of field ranged from $0.8 \mu \mathrm{m}$ to 3.3 $\mu \mathrm{m}$ depending on the width of the aperture. In acquiring images, the aperture for each channel was set at the smallest possible opening. With the aperture openings employed, the FITC depth of field was usually $1.5-2 \mu \mathrm{m}$ and the Texas red depth of field was usually below $1.0 \mu \mathrm{m}$. Although the depths of field for the two channels often differed, both optical sections were centered at the same section depth. Thus, the optical sections were always in vertical alignment. When the depth of field imaged was less than the imaging interval $(1.5 \mu \mathrm{m}$ in the z-axis; see above), then the intervening depth of tissue was not scanned.

In order to produce a coronal reconstruction of the labeled neuron, the optical sections from each scanned field were projected and compiled into a single image. Projected images were then photographed and a montage of adjacent fields was used to produce a reconstruction of the labeled somatodendritic field.

Single images (i.e., a $1.5 \mu \mathrm{m}$ slice) from each of the two channels, centered on the same z-axis plane, were then merged and appositions between the soma (Texas red) and the ENK-IR profiles (FITC) were mapped onto the cell reconstruction. Appositions were determined by visual inspection. In ambiguous cases, an analysis of pixel intensity and location was performed (see below). The area of each profile that apposed a labeled element was measured.

Morphometry and neuronal modeling. The total somatic surface area was calculated from measurements of the cellular perimeter in each of the optical sections where the soma was present. Due to the optical 

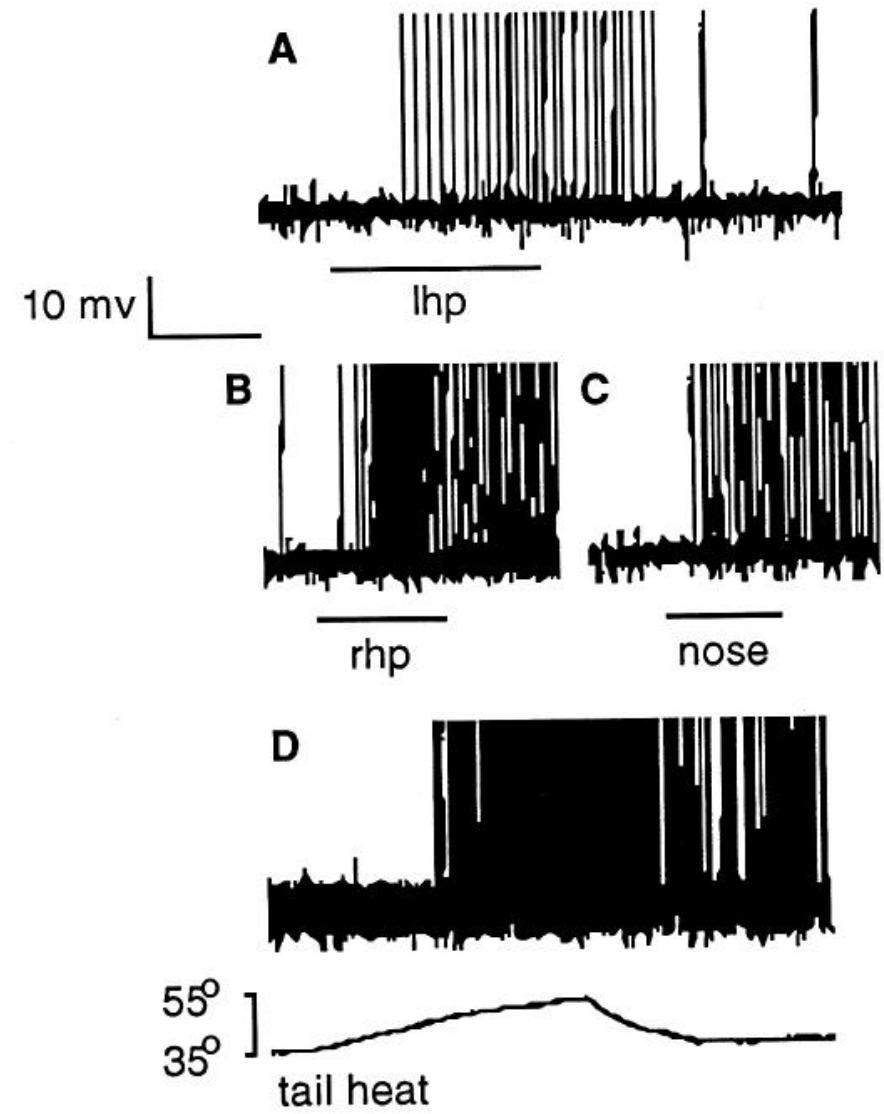

Figure 1. Intracellularly recorded responses of an RVM neuron (resting membrane potential, $-55 \mathrm{mV}$ ) to noxious stimulation. Since the magnitude of digitized action potentials varies, the top of the recordings is truncated. This cell was excited by pinch of the left hind paw (lhp, $A$ ), pinch of the right hind paw $(r h p, B)$, pinch of the nose $(C)$, and tail heat (D). In $A-C$, the line below the traces denotes the application of the stimulus. In $D$, the tail is heated with a ramp stimulus as shown by the temperature trace. Noise from the tail heater greatly increases the baseline noise in $D$. Time calibration: $A$ and $C, 1 \mathrm{sec} ; B, 2 \mathrm{sec} ; D, 4 \mathrm{sec}$. section sampling used, surface area was calculated as $2 \cdot P$ where $P$ is the perimeter measured in optical sections through the middle of the soma. Sections that contained the top and bottom of the soma contributed both the perimeter and the area of a circle whose diameter is the same as a circle with the measured perimeter.

Total dendritic surface area was calculated as the surface area of a perfect cylinder whose height is equal to the dendritic length, and the cylindrical diameter is the average diameter of the dendritic element.

The efficacy of each apposition was calculated using Rall's (1959) motoneuronal model. Briefly, the following equations were used.

(1) $l=\left[(d / 4)\left(R_{m} / R_{i}\right)\right]^{1 / 2}$, where $R_{m} / R_{i}=72$ and $d$ is the average diameter of the dendrite.

(2) $B_{j}=\left[B_{j+1}+\tan \left(L / l_{j}\right)\right] /\left[1+B_{j+1} * \tanh \left(L_{j} / l_{j}\right)\right]$, where $L_{j}$ is the length of the dendritic segment $j$. The value of $B$ depends on distal branching patterns and is set such that the $B$ value for all terminal branches is zero.

(3) $V_{0} / V_{1}=\cosh \left(L_{0} / l_{0}\right)+B_{1} \sinh \left(L_{0} / l_{0}\right)$.

Efficacy was then defined as $V_{0}^{-1}$. The limitations of Rall's model for simulating RVM neurons are understood by the authors and are discussed in detail elsewhere (S. Potrebic and P. Mason, unpublished observations).

Statistics were performed using the Mann-Whitney $U$ test, except where noted.

\section{Results}

Physiology of cells

In accordance with previous results from this laboratory (Fields et al., 1983a; Mason and Fields, 1989), neurons were classified as on-, off-, or neutral cells. On-cells were excited by a noxious cutaneous pinch or by noxious heat applied to the paws, tail, or head (Fig. 1). Off-cells were inhibited by noxious heat or pinch applied anywhere over the body and head surface. The firing rate of neutral cells was not affected by noxious somatic stimulation.

Neurobiotin filling resulted in an extensive label of the injected neuron and dendrites, including distal dendrites (see Figs. $2,10-12$ ). The studied neurons varied in the size and complexity of their dendritic arbors. All neurons were located in the RVM as defined in Mason et al. (1990) (Fig. 2).

Figure 3 illustrates the use of the CSLM to section a stained neuron optically. The neuron is optically sectioned by using the motorized stage to move the tissue containing the cell in the
A
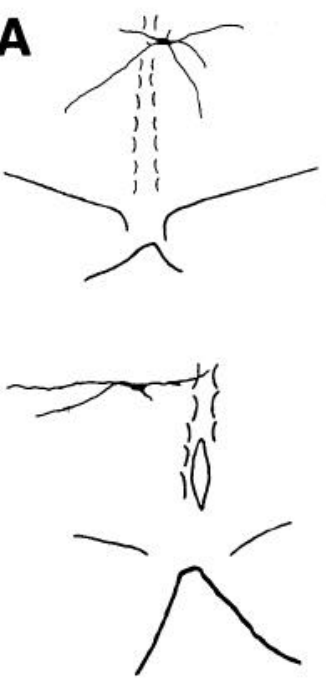

B

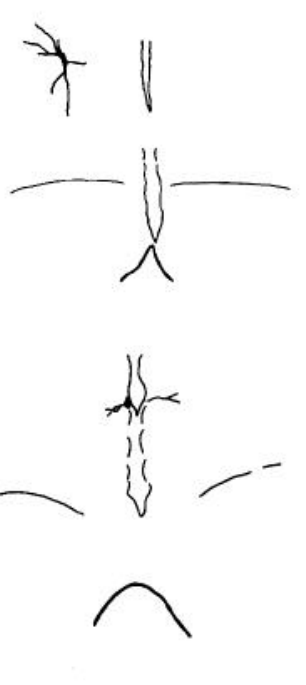

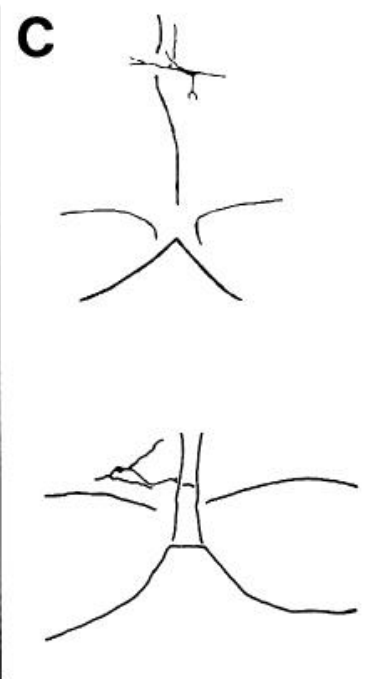

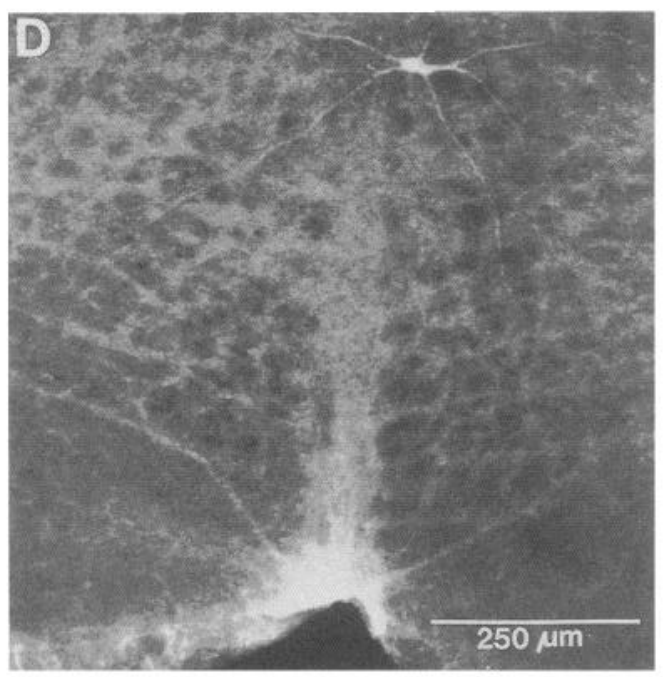

Figure 2. $A-C$, A montage of the nuclear locations of six labeled RVM neurons. All sections are at the level of the facial nucleus. $A$, on-cells; $B$, off-cells; $C$, neutral cells. $D$, A projection of several low-power optical sections through an RVM on-cell, RBA 28-1-1. 

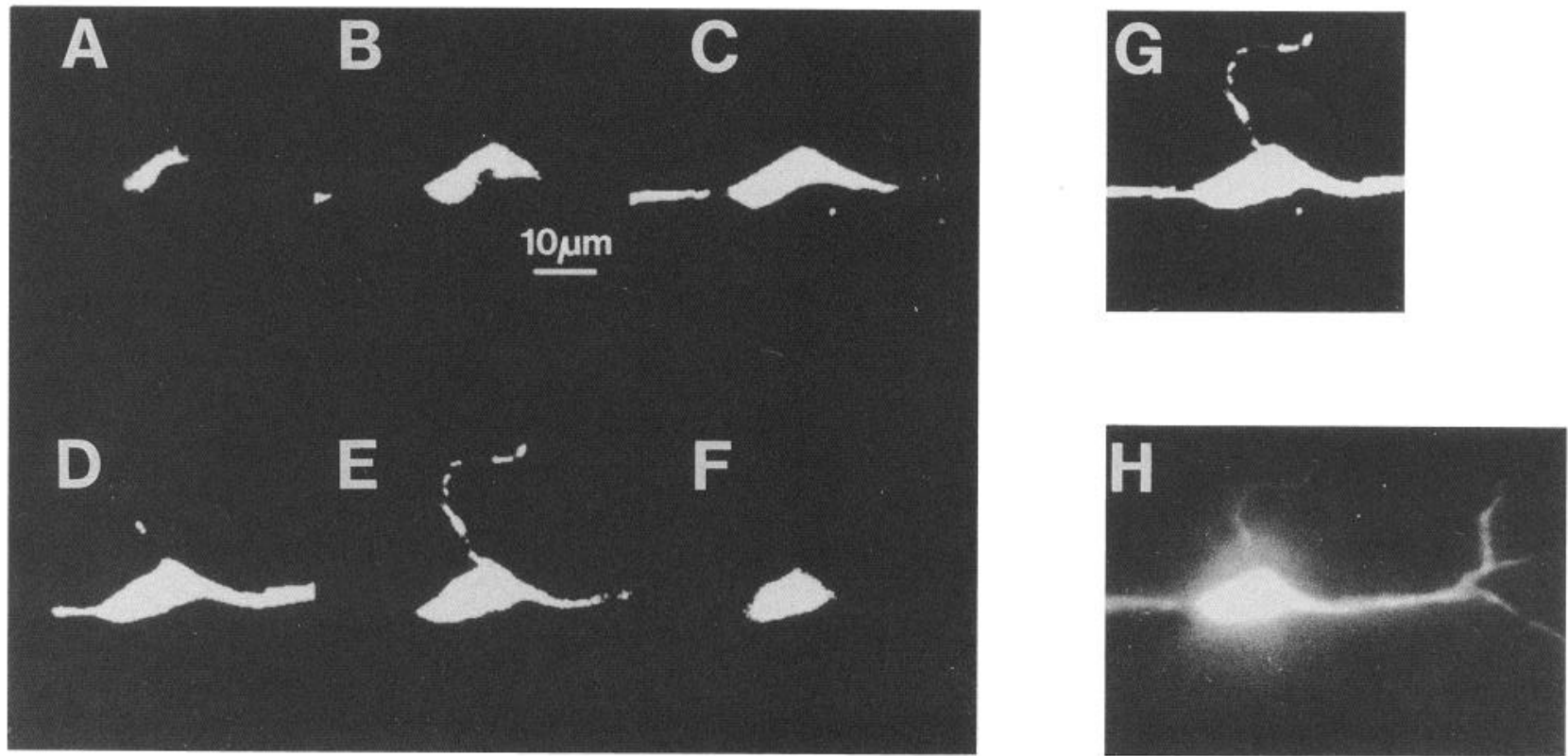

Figure 3. $A-F$, Sequential CSLM optical sections through an RVM on-cell, RBA 24-7-1. These sections were obtained at intervals of $1.5 \mu \mathrm{m}$ (see Materials and Methods). $G$, A projection of the summation of all optical sections shown in $A-F$. $H$, An epi-fluorescent photomicrograph of this same neuron.

depth (z) axis through the focal plane of the microscope. Although some overlap between optical sections can occur at large collection aperture widths (see Materials and Methods), very small apertures were employed for the Texas red channel. Optical sections through the labeled cell were therefore usually under $1.0 \mu \mathrm{m}$.

\section{Enkephalin immunoreactivity in the RVM}

Within the RVM, a fine network of fibers and axonal varicosities was revealed by the immunochemical staining using the enkephalin antibody described in Materials and Methods (Fig. 4). These results are similar to previous reports from numerous laboratories (Khachaturian et al., 1983; Williams and Dockray, 1983).

As seen in Figure 5, ENK-IR profiles typically appear in only one or two optical sections (obtained at $1.5 \mu \mathrm{m}$ intervals). Since the FITC signal was relatively weak, the FITC collection aperture on the CSLM was widened in some cases, thereby increasing the depth of field for each optical section. However, optical sections were never any thicker than $3.0 \mu \mathrm{m}$ and were usually in the range of $1.5-1.8 \mu \mathrm{m}$ thick.

\section{Enkephalin-immunoreactive appositions onto labeled neurons}

Optical sections of the neuron, labeled with Texas red, and the ENK-IR axons, labeled with FITC, were merged (see Materials and Methods). Merged images were used to search for close appositions between ENK-IR profiles and labeled neurons and their dendrites. Examples are seen in Figures 6 and 7. In Figure $7 F-H$, a large profile is seen over several optical sections, but is only apposed to the labeled soma in two of these sections. In other cases, profiles are restricted to the single optical section that contains the site of apposition (see Fig. 7I-J).

The edges of all objects (profiles, cells, dendrites) were defined as the set of pixel positions where the intensity of that object was at the half-maximum of all pixels constituting the object (Pawley, 1990). An ENK-IR profile was considered a bouton if it (1) swelled to at least double the width of the parent fiber, (2) was present on more than one optical section, or (3) was larger than $0.4 \mu \mathrm{m}^{2}$ in cross-sectional area. Appositions were then defined by sites where the edges, of a labeled cell and of an ENKIR bouton, either occupied adjacent pixels or overlapped. This is demonstrated in Figure 8, where the locations of pixels with intensities beyond the half maximal brightness are graphed. The edges of the neuron and of the profile either overlap or appose each other over a distance of more than $1.0 \mu \mathrm{m}$ in the $\mathrm{x}-\mathrm{y}$ plane. In other regions, ENK-IR boutons were seen in proximity, but not in apposition, to a Texas red-labeled element; some of these "near misses" would likely have been labeled appositions using conventional fluorescent microscopy (see examples in Figs. $6 A, D ; 7 F)$. This would almost certainly produce a false-positive error in "near-miss" cases where the labeled cell and the stained bouton are only separated in the z-direction (Fig. 7A-E).

The cross-sectional area of all ENK-IR appositions was measured (Fig. 9). The average size of appositions onto on-cells (1.2 $\pm 0.1 \mu \mathrm{m})$ was significantly larger than that for appositions onto off- and neutral cells $(0.8 \mu \mathrm{m} \pm 0.1)(p<0.001, t$ test $)$.

\section{Distribution of enkephalin appositions on labeled cells}

ENK-IR appositions were observed on somata and dendrites of on-, off-, and neutral cells. Figures 10-12 show the distribution of ENK-IR appositions onto the three types of RVM neurons. It is readily apparent that there are more appositions onto on-cells than onto off- or neutral cells.

Several calculations were made in order to compare quantitatively the number of ENK-IR appositions onto the different classes of RVM cells. Off- and neutral cells were not different in any of the parameters studied and were therefore grouped together for comparison with on-cells. First, the number of dendritic appositions per millimeter of dendrite examined was calculated. The range of ENK-IR apposition density across the oncell population (17.13-30.37 appositions/mm) was higher than 

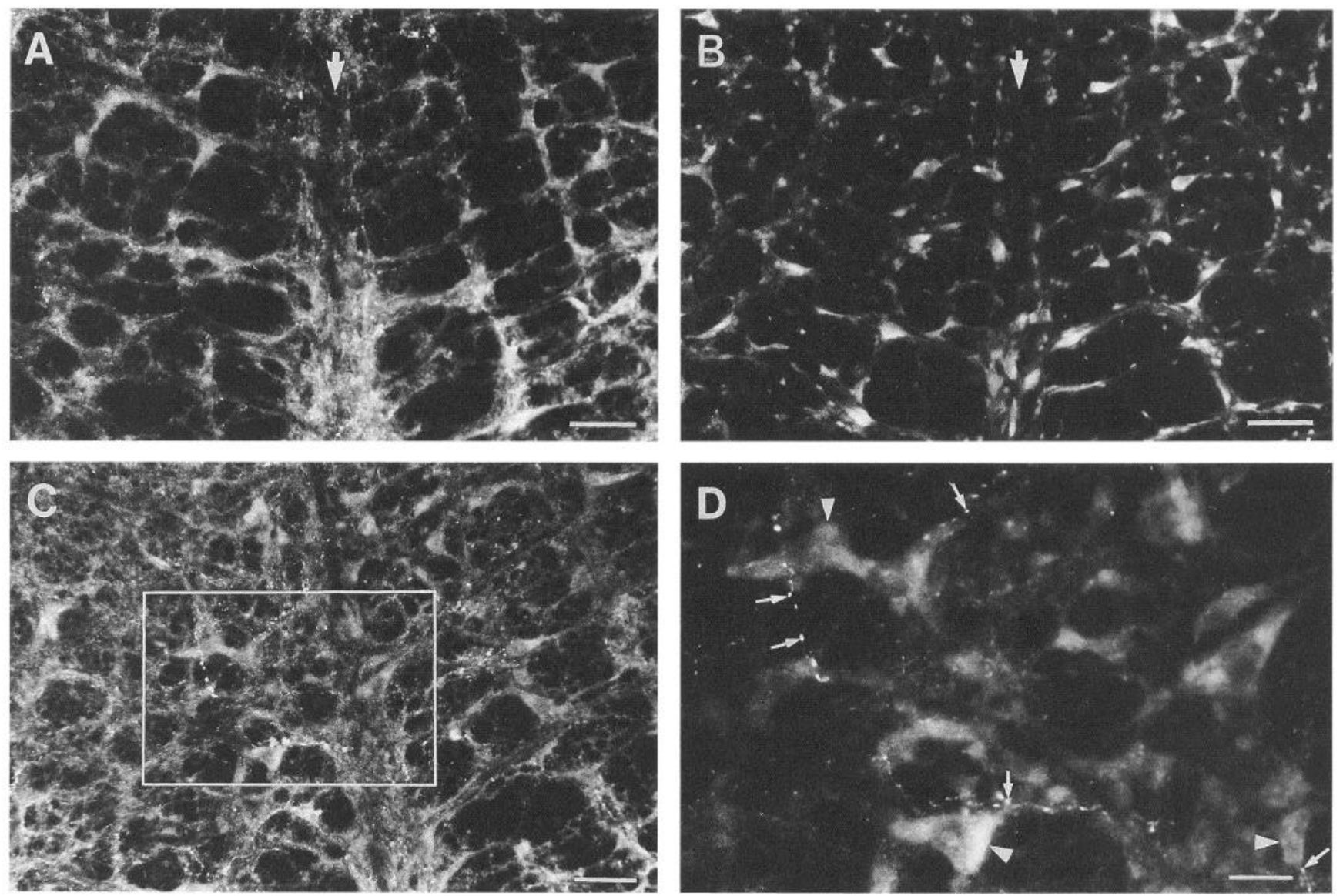

Figure 4. Epifluorescent photomicrographs of the RVM showing the distribution of ENK-IR staining at the level of the facial nucleus. All sections were counterstained with ethidium bromide to visualize somata. Photomicrographs were obtained using a wide-band blue excitation filter. $A$, Lowpower view of ENK-IR fibers along the midline (arrow) of the nucleus raphe magnus. $B$, After preabsorption of the antisera with leu-enkephalin, there is no ENK-IR in the RVM although somata are still visible (due to ethidium bromide staining). $C$ and $D$, The boxed area in $C$ is seen at higher magnification in $D$, which shows the close association of immunoreactive varicosities (arrows) with several somata (arrowheads). Scale bars: $A-C, 50 \mu \mathrm{m} ; D, 20 \mu \mathrm{m}$.

the density for any of the off- or neutral cells (1.92-13.95 appositions $/ \mathrm{mm}$ ). Figure 13 shows that the average density of ENK-IR appositions on RVM on-cell dendrites (18.48 appositions $/ \mathrm{mm})$ is significantly higher than that on off- and neutral cell dendrites (6.91 appositions $/ \mathrm{mm} ; p<0.0013)$. In addition, the average number of somatic contacts per somatic perimeter examined (see Materials and Methods) was much higher for oncells (36.75 appositions $/ \mathrm{mm}$ ) than for off- and neutral cells ( 7.44 appositions $/ \mathrm{mm} ; p<0.0275)$. The difference between on-cell dendritic (18.48 appositions/mm) and somatic (36.75 appositions/mm) ENK-IR density was not significant.

In order to relate apposition distribution to surface area, a measure that encompasses both dendritic width and dendritic length, the total surface area of the dendrites examined was estimated (see Materials and Methods). Figure 14 shows that the average number of ENK-IR appositions per square millimeter of dendritic surface area examined is significantly higher on on-cells (3921 appositions $/ \mathrm{mm}^{2}$ ) than on off- and neutral cells (1328 appositions $\left./ \mathrm{mm}^{2} ; p<0.0031\right)$. The average density of ENK-IR appositions onto the soma of on-cells (5072 appositions $\left./ \mathrm{mm}^{2}\right)$ is also significantly higher than onto off- and neutral cells $\left(1042\right.$ appositions $\left./ \mathrm{mm}^{2} ; p<0.0275\right)$. The surface area density of appositions onto no neutral cells and only one off-
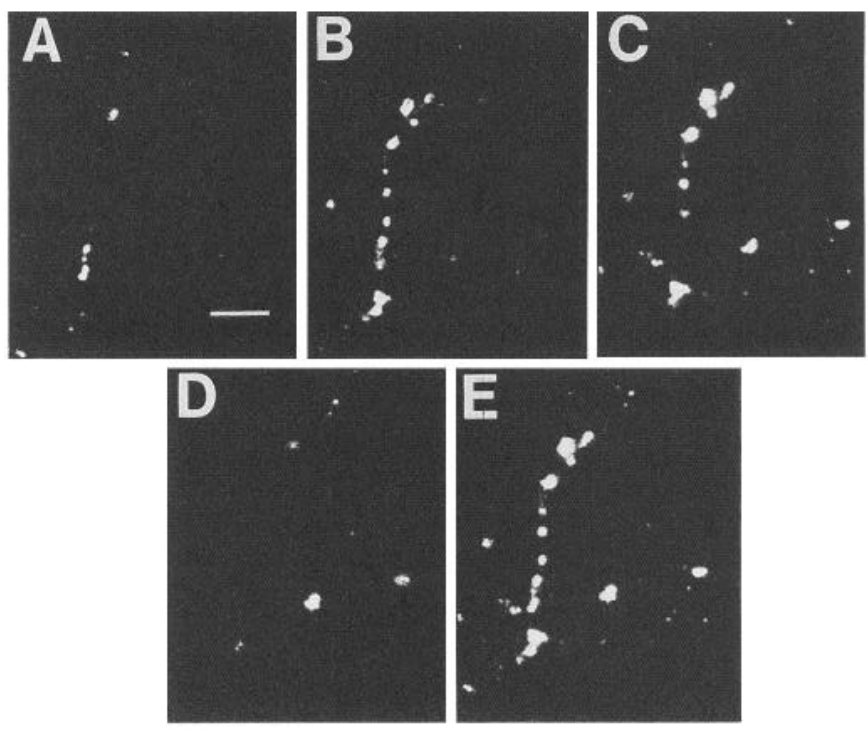

Figure 5. $A-D$, Individual CSLM optical sections through a "string" of ENK-IR varicosities. $E$, A projection of the summation of all optical sections shown in $A-D$. Scale bar, $5 \mu \mathrm{m}$. 

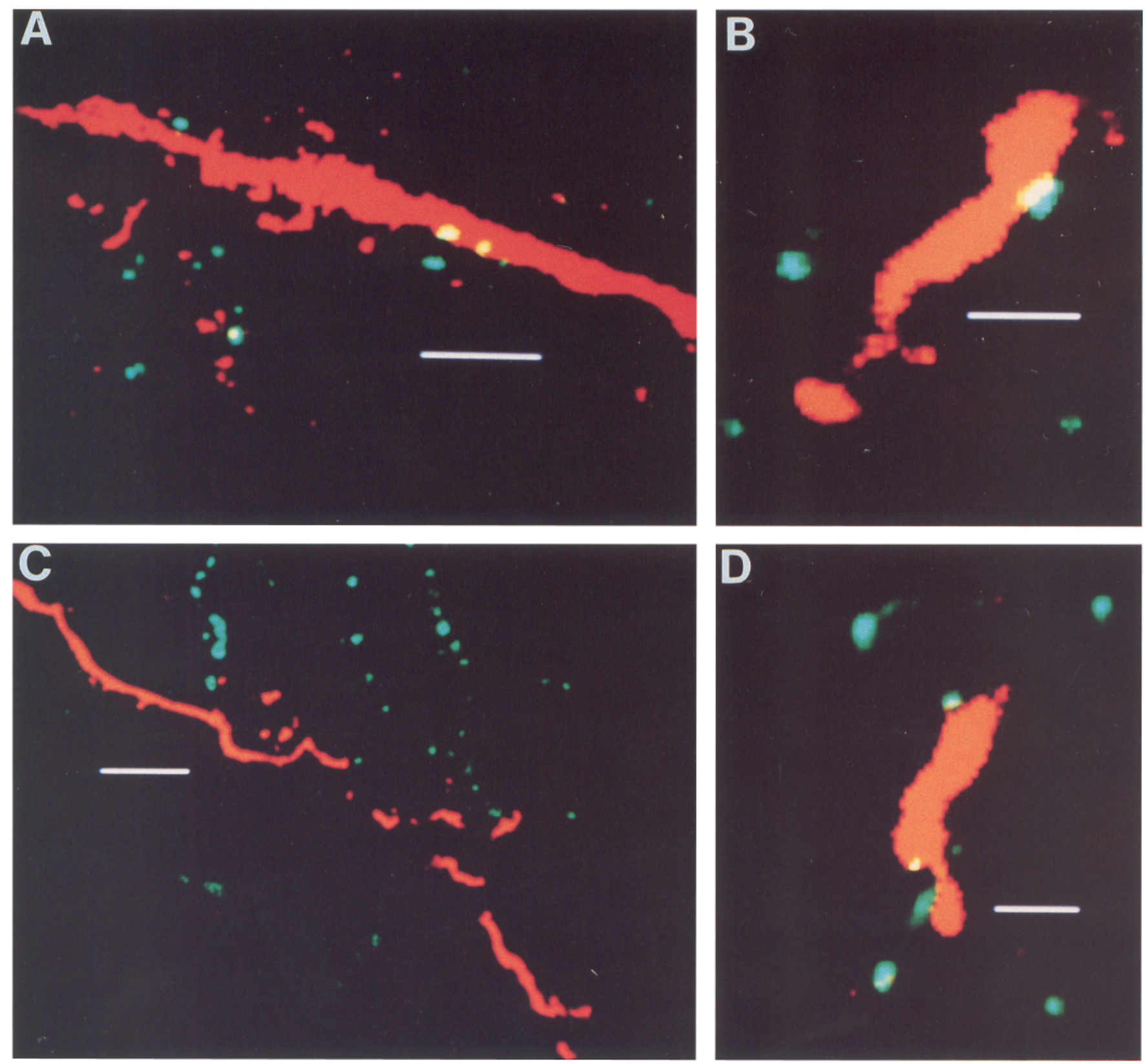

Figure 6. Merged, single-plane CSLM images from an RVM on-cell, RBA 28-1-1. Numerous appositions are seen in $A, B$, and $D$. "Near misses" are seen in $A$ and $D$. The image in $C$ shows a dense field of enkephalin where no appositions are apparent. Scale bars: $A, 5 \mu \mathrm{m} ; B$ and $D, 2 \mu \mathrm{m} ; C$, $10 \mu \mathrm{m}$.

cell (2868 appositions $/ \mathrm{mm}^{2}$ ) was within the range for on-cells (2789-7041 appositions $/ \mathrm{mm}^{2}$ ).

The above measures of linear and areal density do not measure any possible inhomogeneity in the density of appositions within the somatodendritic arbor of labeled cells. Since the pattern of RVM neuronal dendritic branching is such that dendrites of any given order are a heterogeneous class (Potrebic and Mason, unpublished observations), apposition density was not an- alyzed according to dendritic order. Instead, we chose to measure the distribution of appositions by calculating the potential effect that a given voltage applied at each apposition would have at a distant site of summation. This electrotonic measure takes into account dendritic length, width, and branching. Rall's equations for an equivalent cylinder were used to model the neurons and to estimate the efficacy of an input at each apposition (see Materials and Methods). Although several assumptions that are

Figure 7. $A-E$, An example of a "near miss" in the z-plane. $A-D$ show individual CSLM optical sections through a labeled process (RBA 25-3-1, a neutral cell) and a profile $(A, B) . E$, In the summation of the four optical sections in $A-D$, which represents a total z-axis thickness of $6.0 \mu$ m, an apposition is apparent. $F-H$, An apposition onto on-cell RBA 24-7-1 is seen in three consecutive optical sections. $I$ and $J$, Optical sections through an on-cell dendrite (RBA 11-4-1) that receives an enkephalin apposition (only present in $J$ ). Scale bars: $A, 1 \mu \mathrm{m}$ for $A-E ; F, 5 \mu \mathrm{m}$ for $F-$ $H ; I, 10 \mu \mathrm{m}$ for $I$ and $J$. 

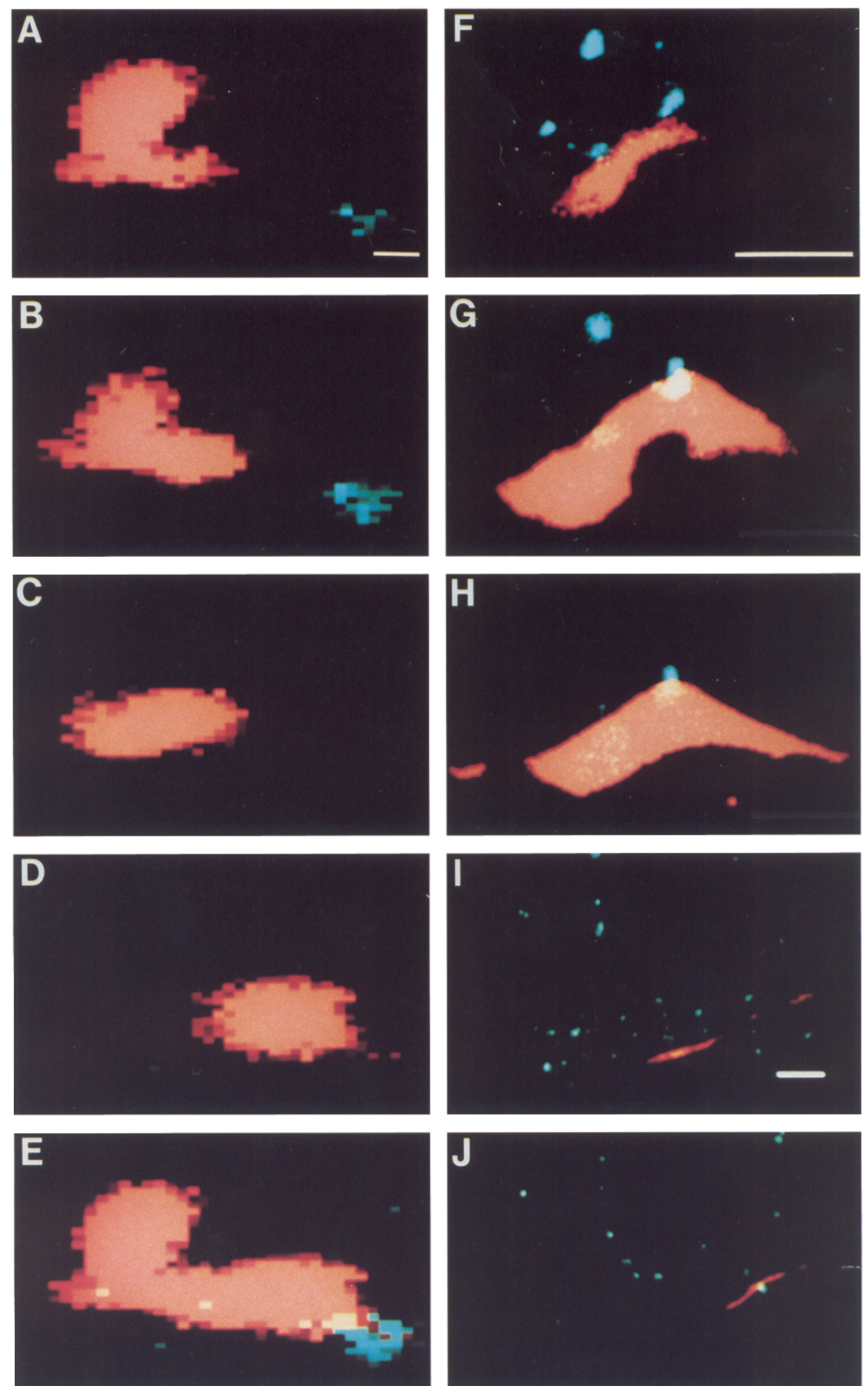

J

8 
Figure 8. $A$, Three-dimensional graphs of the distribution of pixel intensity within a single CSLM optical section. The base of the graphs represents $50 \%$ of maximal intensity, and the upper limit shows $100 \%$ of maximal intensity. The upper graph shows the pixel intensity of an on-cell, RBA 24-7-1, and the lower graph represents the intensity of a profile present in the same optical section. $B$, The edges of a soma (solid circles) and a profile (open squares) are graphed two dimensionally. The line beneath each graph is $1.0 \mu \mathrm{m}$ and is placed in the same position in each graph. The apposition (between arrows) in the left graph is a representation of the apposition seen in $A$. The area represented in these graphs is also seen in Figure $7, F$ (right), $G$ (middle), and $H$ (left). All graphs are rotated $270^{\circ}$ relative to Figure 7.
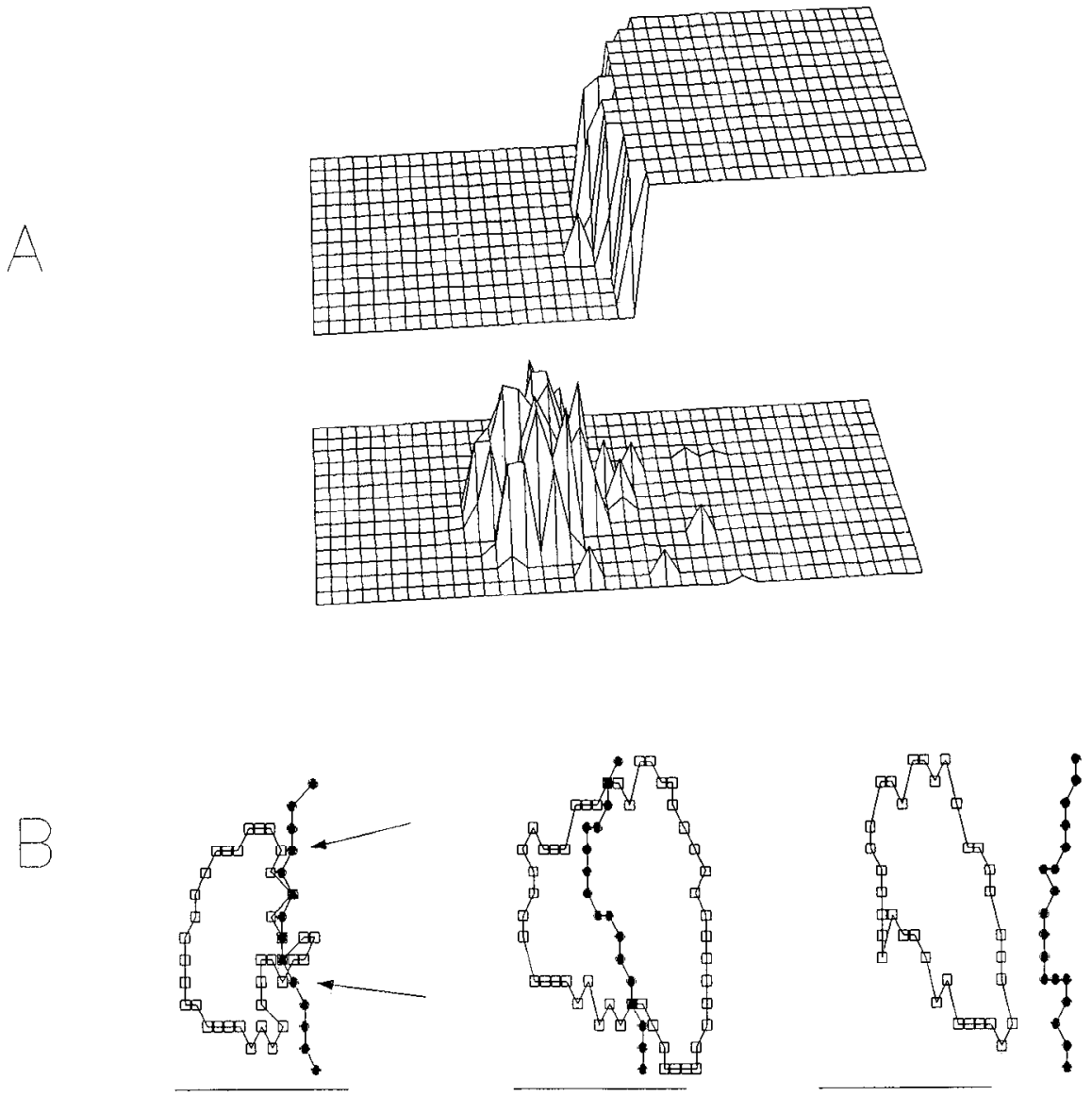

made in this method are improbable in the present sample of neurons (a full discussion of this issue will appear in the near future, Potrebic and Mason, in preparation), the model provides an estimate of the relative electrotonic distance of different dendritic elements. Using the equivalent cylinder method, the voltage required at each apposition to produce 1 unit of voltage at the soma was calculated; the reciprocal of this voltage was termed

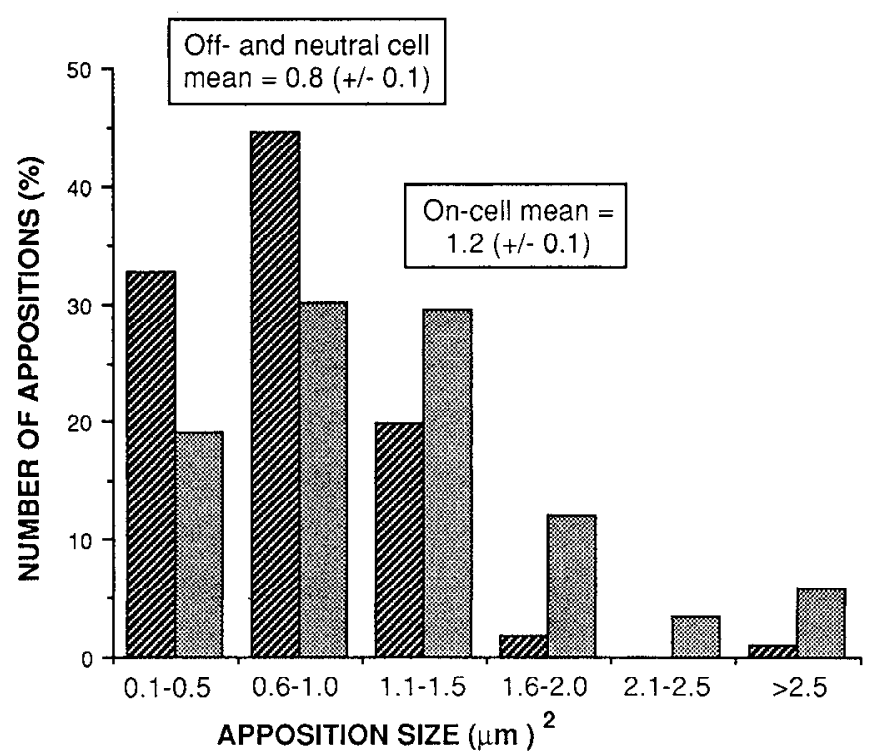

Figure 9. The distribution of profile size (cross-sectional area) for appositions onto on-cells and onto off- or neutral cells. the efficacy of the apposition. The density of appositions, with a given efficacy, per unit of surface area was then calculated (Fig. 15). The density of ENK-IR appositions, with efficacies of $83-100 \%$ and of $62-66 \%$, was significantly greater for on-cells than for off- and neutral cells $(p<0.0016)$. The density of ENK-IR appositions with intermediate efficacy values, between $62 \%$ and $83 \%$, was not different among cell classes. There were not enough appositions with efficacies of less than $62 \%$ to determine whether any differences existed between the cell classes.

\section{Control observations}

Since the mapping of appositions onto the different cell classes was performed by an unblinded observer (P.M.), several control observations were made. In order to determine how the unblinded observer's bias might have affected the results, a blinded observer read optical sections (frames) that had previously been read by the unblinded observer.

In the first series of control observations, 10 single-plane merged CSLM frames were sampled randomly from all on-cell frames and 10 frames were chosen randomly from all off- and neutral cell frames. All ENK-IR profiles identified as appositions by the unblinded observer $(N=3)$ were also labeled as such by the blinded observer (Table 1). In 15 frames, both the blinded and unblinded observers found no appositions. Five ENK-IR profiles called appositions by the blinded observer were not identified by the unblinded observer.

Although the above results suggested that the blinded observer labeled fewer profiles as appositions than the unblinded observer, there were too few appositions in the images to determine whether an observer bias existed. Therefore, in order 


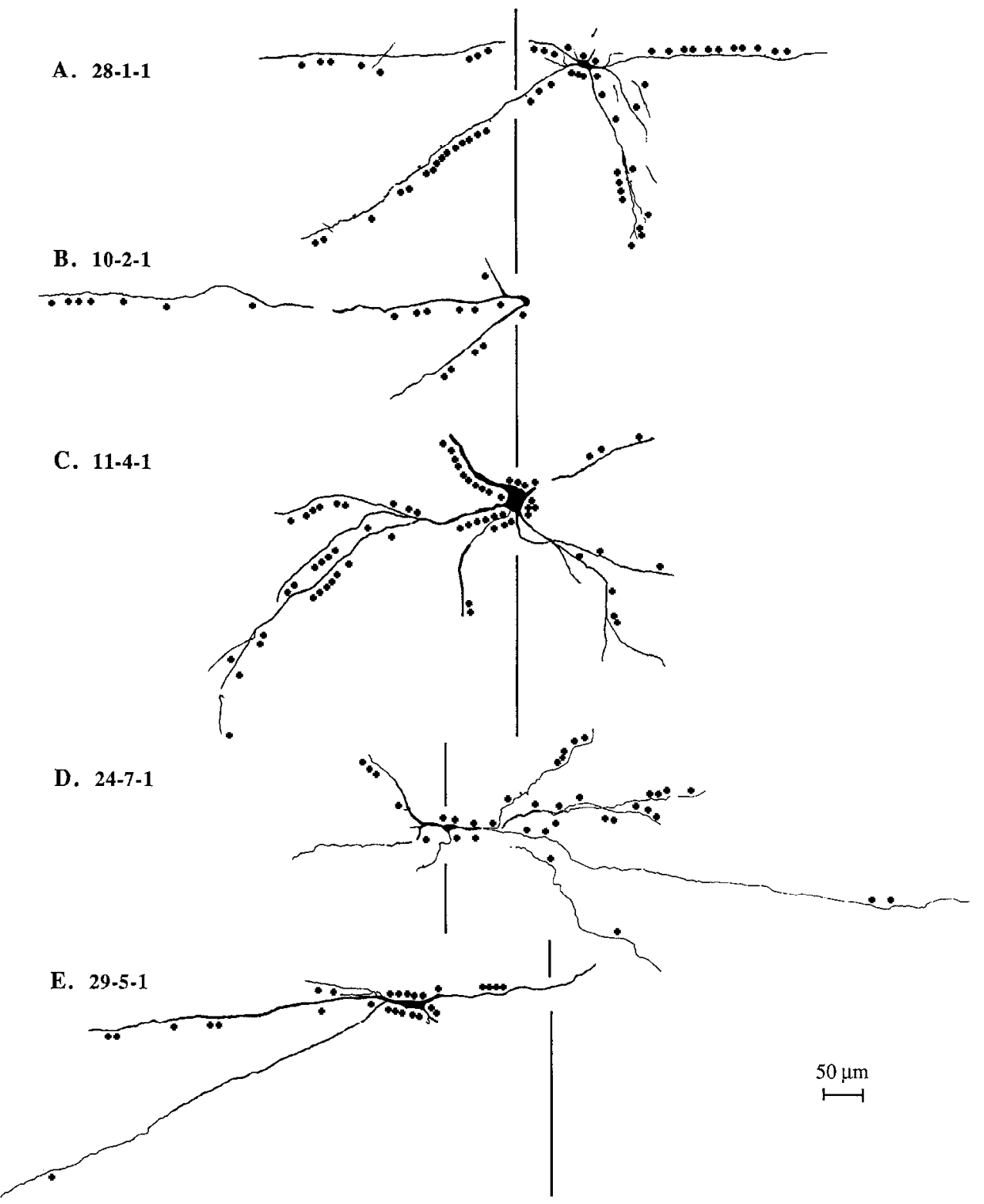

Figure 10. A montage of five RVM on-cells shows the distribution of enkephalin appositions (dots) onto these neurons. The midline is shown as a solid straight line in each case. One oncell is not included since it could not be reliably reconstructed.

to extend our observations to a larger number of appositions in each cell class, for each neuron studied $(N=14)$, one frame was chosen randomly from those frames that were judged to contain at least one apposition by the unblinded observer. These frames were then read by the blinded observer. Twenty appositions contained in 13 files were found by both observers. Three appositions were found only by the blinded observer, all among the off- and neutral cells, and four appositions were found only

Table 1. Control observations of unshifted images (see control observations section in Results)

\begin{tabular}{|c|c|c|}
\hline $\begin{array}{l}\text { Un- } \\
\text { blinded } \\
+ \\
\text { Blinded } \\
-\end{array}$ & $\begin{array}{l}\text { Un- } \\
\text { blinded } \\
- \\
\text { Blinded } \\
+\end{array}$ & $\begin{array}{l}\text { Un- } \\
\text { blinded } \\
+ \\
\text { Blinded } \\
+\end{array}$ \\
\hline $0(0)$ & $2(1)$ & $3(2)$ \\
\hline $0(0)$ & $3(2)$ & $0(0)$ \\
\hline \multicolumn{3}{|c|}{$\mathrm{n}^{a}$} \\
\hline $0(0)$ & $3(2)$ & $9(8)$ \\
\hline $4(3)$ & $0(0)$ & $11(5)$ \\
\hline
\end{tabular}


A. 20-5-1

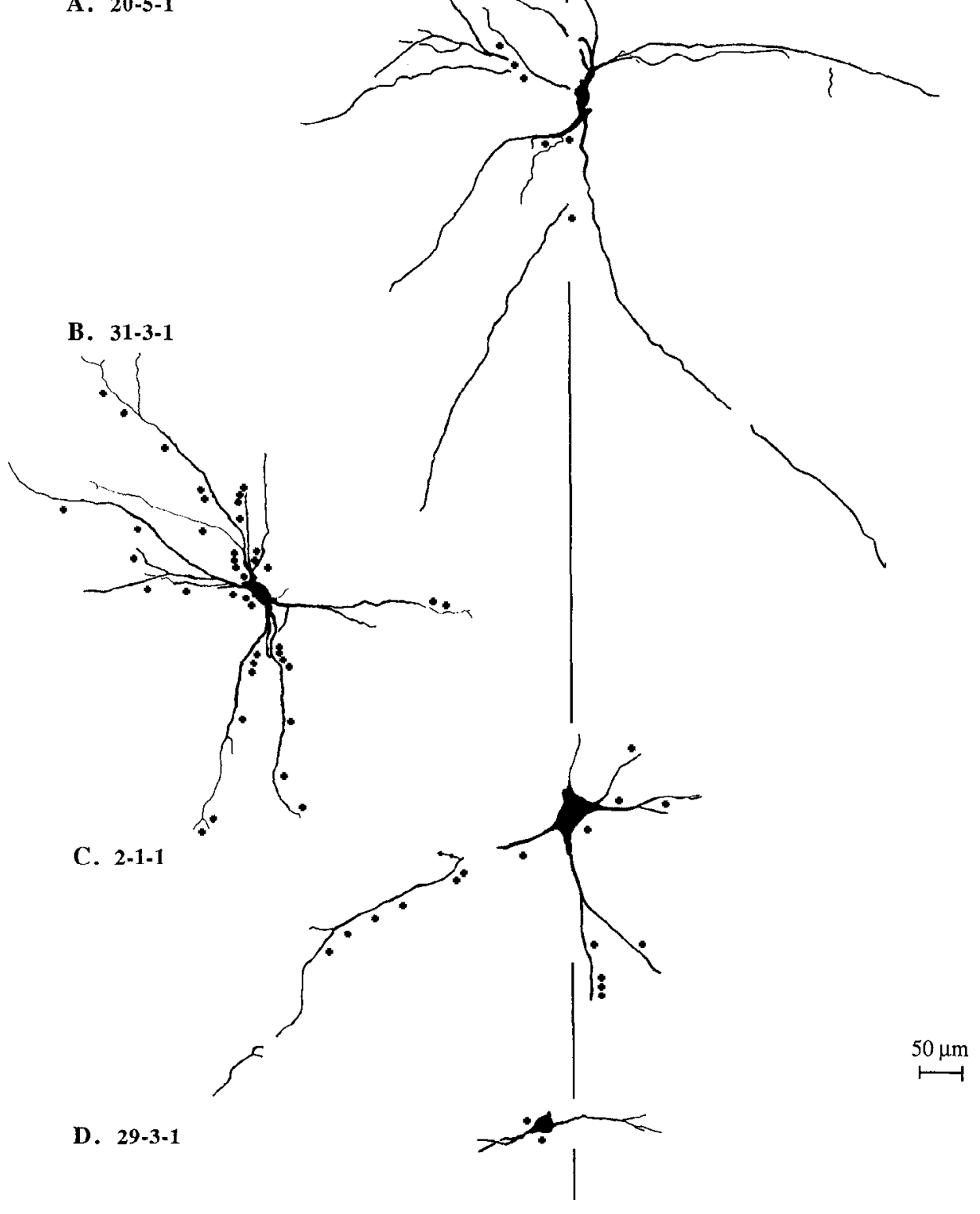

Figure 11. A montage of four RVM off-cells, as in Figure 10.

by the unblinded observer, all among the on-cells. These results indicate that there was a bias in the unblinded observer's observations.

The discordant findings between observers were typically due to differing judgements in identifying ENK-IR profiles. For instance, several profiles that were labeled as appositions only by the blinded observer were either very small or of low intensity. In other cases, several nonround objects that fluoresced with FITC were identified as appositions by the unblinded observer but not by the blinded observer.

To estimate the chances that a contact was chosen because of the unblinded observer's bias, a third set of control observations were made. A blinded observer looked for appositions in images where a Texas red optical section containing part of a Neurobiotin-labeled cell was merged with an FITC optical section containing ENK-IR taken from a different focal plane, $6 \mu \mathrm{m}$ rostral or caudal to the Texas red section (Table 2). These "frame-shifted" merges were then read by the blinded observer; the blinded observer did not know which frames were unshifted and which were shifted. Although the blinded observer found 23 appositions in the unshifted frames, she only observed 6 appositions in the shifted frames. The density of appositions (per length labeled element) in the shifted merges is a measure of the chance identification of an ENK-IR profile as an apposition. The density of "appositions" in the shifted and unshifted frames was 8.28 and 31.74 appositions $/ \mathrm{mm}$, respectively. It is important to note that the unblinded observer found 24 appositions in the unshifted frames. The densities of ENK-IR profiles labeled as appositions by the blinded and unblinded observers were therefore not different (Table 2). These results imply that the chance occurrence of ENK-IR profiles close enough to labeled neurons to be identified as appositions is unlikely to account for the higher density of ENK-IR appositions onto oncells reported in this study. In contrast, the density of ENK-IR 
A. 34-2-1

B. $33-4-1$

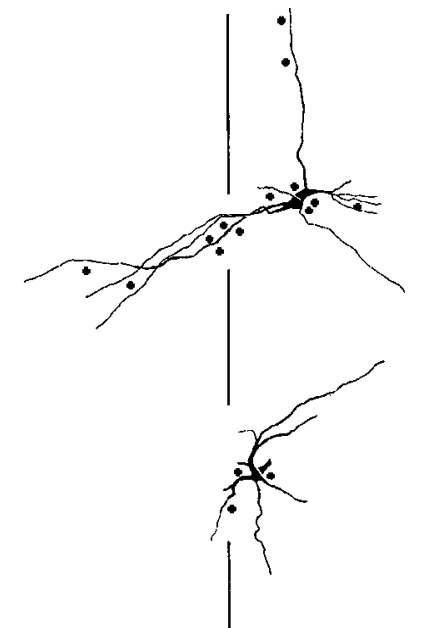

C. 32-5-1

D. $25-3-1$

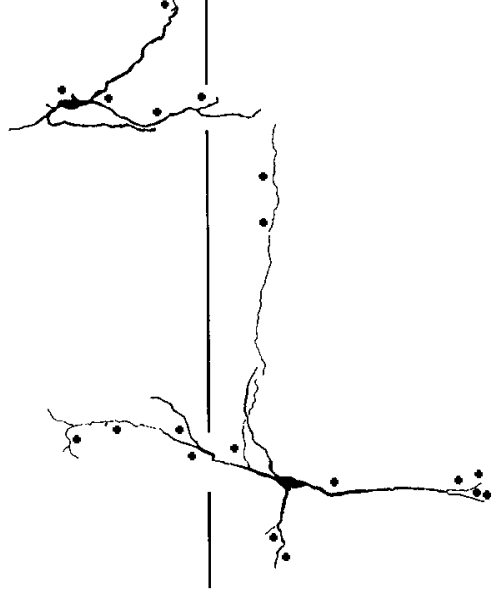

Figure 12. A montagc of four RVM neutral cclls, as in Figure 10.

appositions onto off- and neutral cells is about the same as the density of apparent appositions created by chance in shifted merges.

\section{Discussion}

In the present study, the CSLM was used to identify appositions between intracellularly labeled neurons and immunoreactive profiles in 1-2 $\mu \mathrm{m}$ optical sections. The CSLM allows greater

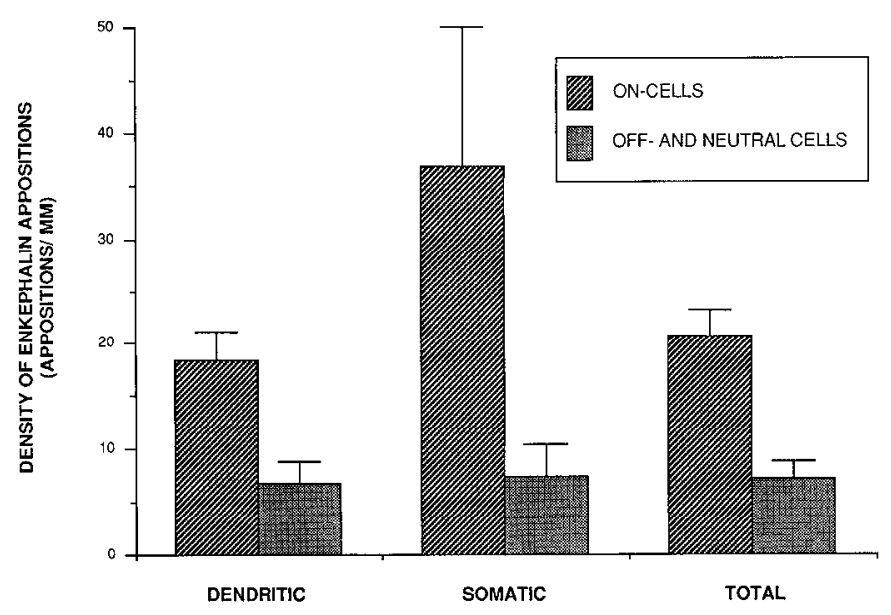

Figure 13. Graph of the dendritic, somatic, and total density of appositions (per $\mathrm{mm}$ ) for on-cells (hatched bars) and for off- and neutral cells (solid bars). The error bars represent one standard error above mean.

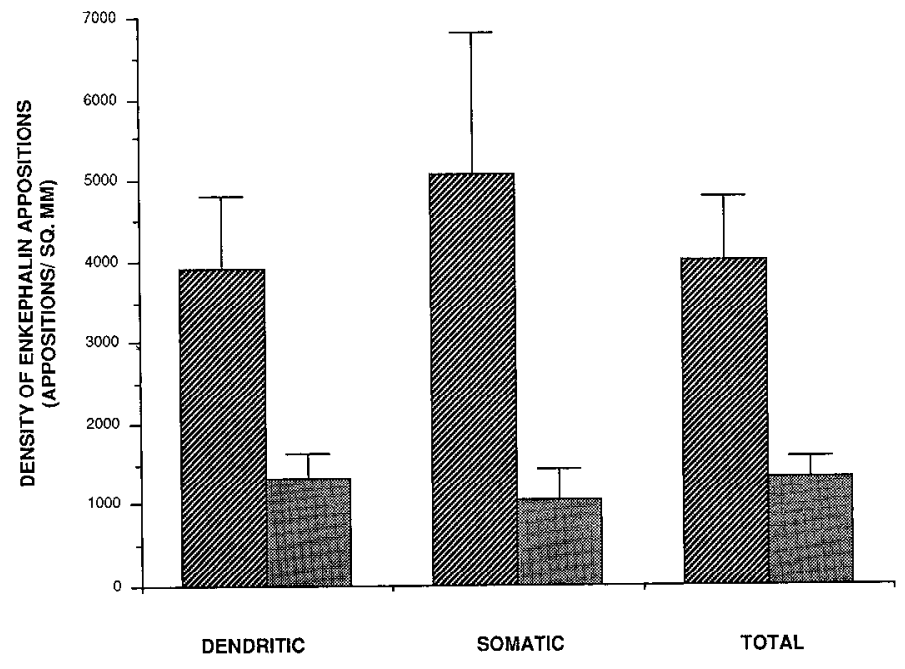

Figure 14. Graph of dendritic, somatic, and total density (per $\mathrm{mm}^{2}$ ) for on-cells (hatched bars) and for off- and neutral cells (solid bars). The error bars represent one standard error above mean.

resolution than conventional light microscopy (either fluorescent or transmission), particularly in the z-axis of sections that are more than $2 \mu \mathrm{m}$ in thickness. Due to the ability to section material optically, the preparation of tissue for the CSLM is less labor intensive than for electron microscopy, which requires that ultrathin sections be physically cut. However, the CSLM does not provide the ultrastructural resolution that the electron microscopic method allows. Thus, it is unclear which of the appositions found by the CSLM represent synaptic contacts. This is an important issue that we hope to address in the future.

In the present study, the CSLM was used to analyze the density and pattern of cytochemically defined inputs onto a labeled neuron and correlate this information with a cell's physiological activity.

\section{Actions of opioid peptides on RVM on-cells}

The present results demonstrate that RVM on-cells receive a significantly higher density of ENK-IR appositions than RVM

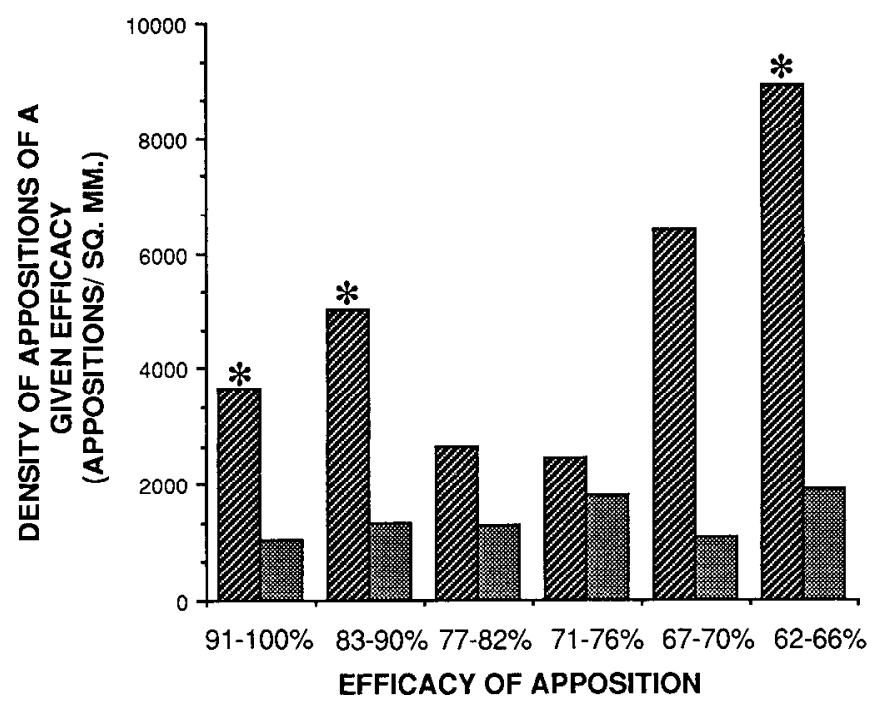

Figure 15. Graph of density of appositions with a given efficacy (see Materials and Methods) for on-cells (hatched bars) and for off- and neutral cells (solid bars). The asterisks indicate statistical significance. 


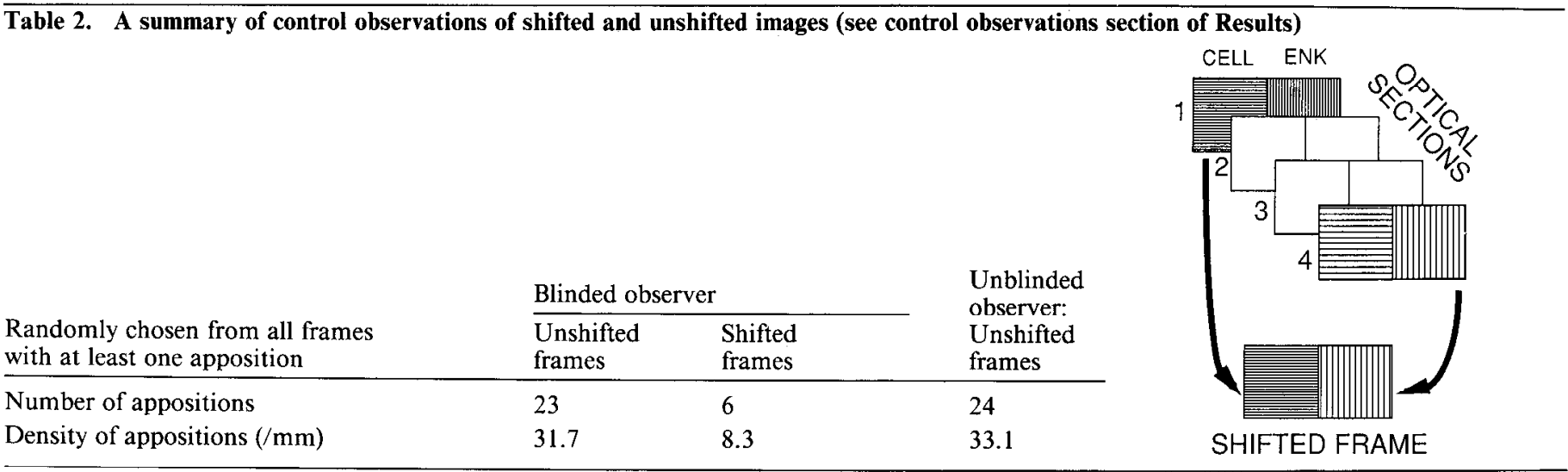

off- or neutral cells. The density of appositions onto on-cells is also higher than would be expected by chance (see above). These results provide an anatomical substrate for the direct inhibition of on-cell activity by an endogenous opioid peptide. In support of this idea, opioids directly hyperpolarize a population of neurons recorded in an RVM slice preparation (Pan et al., 1990). Although these neurons were not recorded in vitro and therefore not characterized as on-, off-, or neutral cells, it is likely that the population of cells hyperpolarized by opioids contains at least some on-cells. In vivo evidence for direct opioid inhibition of on-cells comes from the finding that iontophoretically applied morphine inhibits the spontaneous, sensory-evoked and glutamate-induced activity of RVM on-cells (Heinricher et al., 1992). A direct opioidergic inhibition of RVM on-cells is also in agreement with previous in vivo studies, showing that opioid actions on neurons in other CNS regions are inhibitory (Nicoll et al., 1980; Simonds, 1988; Behbehani et al., 1990).

\section{Actions of opioid peptides on RVM off-and neutral cells}

ENK-IR appositions onto off- and neutral cells were observed in the present study, but at a significantly lower density than were observed onto on-cells. It is possible that the appositions found onto off- and/or neutral cells represent an artifact of chance occurrence. This idea is supported by the finding that the density of appositions in shifted sections $(8.28 / \mathrm{mm})$ (see Results) is similar to that found onto off- and neutral cells in unshifted frames $(7.44 / \mathrm{mm})$.

Although off-cells are excited by opioids whether systemically administered or microinjected into the PAG or RVM, iontophoresis of morphine does not alter off-cell activity. Furthermore, opioids rarely have direct excitatory effects on single CNS neurons. Thus, it is likely that opioid excitation of off-cells results from disinhibition. In fact, recent evidence supports the hypothesis that off-cells receive an inhibitory input from GABAergic on-cells, which in turn are directly inhibited by opioids (Pan et al., 1990; Fields et al., 1991; Heinricher et al., 1991; Mason et al., 1991). Since the opioid excitation of off-cells is likely indirect, it is not surprising that off-cells receive relatively few ENK-IR appositions.

Although it is likely that the indirect excitation of off-cells by opioids involves inhibition of a GABAergic interneuron, it is also possible that opioid actions are mediated by an interneuron with a different inhibitory neurotransmitter. Since enkephalin has inhibitory effects on cells within the RVM, it is possible that the neuron inhibited by enkephalin is, itself, an enkephalin interneuron. This may occur in the midbrain PAG where en- kephalin terminals have been shown to synapse onto enkephalin-containing cells (Williams and Beitz, 1990). Whether such a relationship exists in the RVM is unknown as little work has been done on the ultrastructural characterization of enkephalin in this region. If the inhibitory interneuron in the proposed disinhibitory circuit were enkephalinergic, one would expect to see enkephalin contacts onto off-cells. Since the density of ENKIR appositions onto off-cells observed in the present study is not above the level of chance occurrence, our data do not support this possibility. Indeed, the present results suggest that if opioids inhibit an enkephalinergic interneuron, it is a rare occurrence.

As with off-cells, the density of ENK-IR appositions onto neutral cells was not different from the level of chance occurrence. Thus, it is possible that the ENK-IR appositions observed onto neutral cells do not represent a functional input. Indeed, it is unclear what function ENK-IR appositions onto neutral cells would serve, as neutral cells do not respond to morphine applied systemically, by microinjection into the PAG, or by iontophoresis (see introductory remarks).

\section{Source of enkephalin varicosities}

ENK-IR fibers and varicosities in the RVM are likely to originate from neurons in the RVM and neighboring raphe and reticular nuclei. The endogenous enkephalin peptides contained within RVM cells and terminals include met- and leu-enkephalin, BAM-22P, met-enkephalin- $\mathrm{Arg}^{6}-\mathrm{Phe}^{7}$, and met-enkephalin- $\Lambda \mathrm{rg}^{6}-\mathrm{Gly}^{7}-\mathrm{Leu}^{8}$ (Khachaturian et al., 1983; Williams and Dockray, 1983; Guthrie and Basbaum, 1984), all of which are likely to be recognized by the antibody used in the present study (see Materials and Methods). Different endogenous opioid peptides may be contained in afferents that appose specific RVM cell type(s).

It is surprising that met-enkephalin has been reported to be released within the lateral RVM by noxious thermal stimulation (Kuraishi et al., 1984). Noxious stimulation is also reported to evoke enkephalin release in the PAG and spinal subarachnoid space (Llorens-Cortes et al., 1989; Lucas and Yaksh, 1990). Since on-cells have an excitatory response to noxious stimulation and are inhibited by opioids, this finding is paradoxical. However, the effect on nociceptive reflexes of the stimulation used to evoke enkephalin release is unclear. The prolonged stimulation paradigms employed may have produced a stress- or environmentally induced antinociception. If this were the case, the enkephalin release would be associated with antinociception and thus, perhaps, with decreased firing of on-cells. It is therefore 
crucial that future studies simultaneously examine the effect of stimulation on an animal's nociceptive responsiveness and the effect of naloxone on this responsiveness, while measuring endogenous opioid release.

\section{Summary}

A CSLM analysis of endogenous ENK-IR terminations onto physiologically characterized neurons reveals a differential distribution of opioid afferents onto RVM on-, off-, and neutral cells. On-cells receive significantly more ENK-IR appositions than do other RVM cell types. Furthermore, on-cells are the only RVM cell class that receives more ENK-IR appositions than would be expected by chance. This is consistent with the hypothesis that within the RVM, opioids produce antinociception through a direct inhibition of on-cells. Subsequent to this opioid inhibition, GABA-containing on-cells are hypothesized to decrease their inhibitory drive onto off-cells, resulting in their excitation. The direct inhibition of on-cells and the indirect excitation of off-cells likely produce antinociception through a decrease in on-cell nociceptive facilitation and an increase in off-cell nociceptive inhibition.

\section{References}

Akil H, Watson SJ, Young E, Lewis ME, Khachaturian H, Walker JM (1984) Endogenous opioids: structure and function. Annu Rev Neurosci 7:223-255.

Al-Rodhan N, Chipkin R, Yaksh TL (1990) The antinociceptive effects of SCH-32615, a neutral endopeptidase (enkephalinase) inhibitor, microinjected into the periaqueductal gray, ventral medulla and amygdala. Brain Res 520:123-130.

Azami J, Llewelyn MD, Roberts MHT (1982) The contribution of nucleus reticularis paragigantocellularis and nucleus raphe magnus to the analgesia produced by systemically administered morphine, investigated with the microinjection technique. Pain 12:229-246.

Basbaum AI, Besson JL (1991) Towards a new pharmacotherapy of pain. Chichester: Wiley.

Basbaum AI, Fields HL (1984) Endogenous pain control systems: brainstem spinal pathways and endorphin circuitry. Annu Rev Neurosci 7:309-338.

Bederson JB, Fields HL, Barbaro NM (1990) Hyperalgesia during naloxone-precipitated withdrawal from morphine is associated with increased on-cell activity in the rostral ventromedial medulla. Somatosens Mot Res 7:185-203.

Behbehani MM, Jiang M, Chandler SD (1990) The effect of [met]enkephalin on the periaqueductal gray neurons of the rat: an in vitro study. Neuroscience 38:373-380.

Cheng ZF, Fields HI, Heinricher MM (1986) Morphine microinjected into the periaqueductal gray has differential effects on three classes of medullary neurons. Brain Res 375:57-65.

Cuello $\Lambda$ C, Milstein C, Couture R, Wright B, Priestley JV, Jarvis J (1984) Characterization and immunocytochemical application of monoclonal antibodies against enkephalins. J Histochem Cytochem 32:947-957

Dickenson AH, Le Bars D (1987) Supraspinal morphine and descending inhibitions acting on the dorsal horn of the rat. J Physiol (Lond) 384:81-107.

Fields HL (1987) Pain. New York: McGraw-Hill.

Fields HL, Bry J, Hentall ID, Zorman G (1983a) The activity of neurons in the rostral medulla of the rat during withdrawal from noxious heat. J Neurosci 3:2545-2552.

Fields HL, Vanegas H, Hentall ID, Zorman G (1983b) Evidence that disinhibition of brainstem neurones contributes to morphine analgesia. Nature 306:684-686.

Fields HL, Heinricher MM, Mason P (1991) Neurotransmitters in nociceptive modulatory circuits. Annu Rev Neurosci 14:219-245.

Gebhart (1982) Opiate and opioid peptide effects on brain stem neurons: relevance to nociception and antinociceptive mechanisms. Pain 12:93-140.

Guthrie J, Basbaum AI (1984) Colocalization of immunoreactive proenkephalin and prodynorphin products in medullary neurons of the rat. Neuropeptides 4:437-445.

Heinricher MM, Barbaro NM, Fields HL (1989) Putative nociceptive modulating neurons in the rostral ventromedial medulla of the rat: firing of on- and off-cells is related to nociceptive responsiveness. Somatosens Mot Res 6:427-439.

Heinricher MM, Haws CM, Fields HL (1991) Evidence for GABAmediated control of putative nociceptive modulating neurons in the rostral ventromedial medulla: iontophoresis of bicuculline eliminates the off-cèll pause. Somatosens Mot Res 8:215-225.

Heinricher MM, Morgan MM, Fields HL (1992) Direct and indirect actions of morphine on medullary neurons that modulate nociception. Neuroscience 48:533-543.

Horikawa K, Armstrong WE (1988) A versatile means of intracellular labeling: injection of biocytin and its detection with avidin conjugates. J Neurosci Methods 25:1-11.

Hughes J (1975) Isolation of an endogenous compound from the brain with pharmacological properties similar to morphine. Brain Res 88 : 295-308.

Jaffe JH, Martin WR (1990) Opioid analgesics and antagonists. In: The pharmacological bases of therapeutics (Gilman AG, Rall IW, Nies AS, Taylor P, eds), pp 485-521. New York: Pergamon.

Jensen TS, Yaksh TL (1986) I. Comparison of antinociceptive action of morphine in the periaqueductal gray, medial and paramedial medulla in rat. Brain Res 363:99-113.

Khachaturian H, Lewis ME, Watson SJ (1983) Enkephalin systems in diencephalon and brainstem of the rat. J Comp Neurol 220:310320 .

Kuraishi Y, Sugimoto M, Hamada T, Kayanoki Y, Takagi H (1984) Noxious stimuli and met-enkephalin release from nucleus reticularis gigantocellularis. Brain Res Bull 12:123-127.

Llorens-Cortes C, Gros C, Schwartz JC, Clot AM, LeBars D (1989) Changes in levels of the tripeptide Tyr-Gly-Gly as an index of enkephalin release in the spinal cord: effects of noxious stimuli and parenterally-active peptidase inhibitors. Peptides 10:609-614.

Lucas D, Yaksh TL (1990) Release in vivo of met-enkephalin and encrypted forms of met-enkephalin from brain and spinal cord of the anesthetized cat. Peptides 11:1119-1.125.

Mansour A, Khachaturian H, Lewis ME, Akil H, Watson SJ (1988) Anatomy of CNS opioid receptors. Trends Neurosci 11:308-314.

Mason P, Fields HL (1989) Axonal trajectories and terminations of on- and off-cells in the cat lower brainstem. J Comp Neurol 288:185207.

Mason P, Floeter MK, Fields HL (1990) Somatodendritic morphology of on- and off-cells in the rostral ventromedial medulla. J Comp Ncurol 301:23-43.

Mason P, Skinner D, Cho HJ, Basbaum AI, Fields HL (1991) Anatomical evidence for GABAergic control of physiologically identified off-cells in the rostral ventromedial medulla. In: Proceedings of the VIIth World Congress on Pain (Bond MR, Charlton JE, Woolf CJ, eds), pp 331-335. Amsterdam: Elsevier.

Murakami S, Okamura H, Yanaihara C, Yanaihara N, Ibata Y (1987) Immunocytochemical distribution of met-enkephalin-Arg ${ }^{6}-\mathrm{Gly}^{7}-\mathrm{Leu}^{8}$ in the rat lower brainstem. J Comp Neurol 261:193-208.

Nicoll RA, Alger BE, Jahr CE (1980) Enkephalin blocks inhibitory pathways in the vertebrate CNS. Nature 287:22-25.

Pan ZZ, Williams JT, Osborne PB (1990) Opioid actions on single nucleus raphe magnus neurons from rat and guinea-pig in vitro. $\mathrm{J}$ Physiol (Lond) 427:519-532.

Pawlcy JB (1990) Fundamental limits in confocal microscopy. In: Handbook of biological confocal microscopy (Pawley JB, ed), pp 1526. New York: Plenum.

Rall W (1959) Branching dendritic trees and motoneuron membrane resistivity. Exp Neurol 1:491-527.

Randich A, Aimone LD, Gebhart GF (1987) Medullary substrates of descending spinal inhibition activated by intravenous administration of [D-Ala $\left.{ }^{2}\right]$ methionine enkephalinamide in the rat. Brain Res 411 : 236-247.

Rosenfeld JP, Huang KH, Xia LY (1990) Effects of single and simultaneous combined nanoinjections of met-enkephalin into rat midbrain and medulla on activity of differentially nociresponsive ventral medullary neurons. Brain Res 508:199-209.

Simon EJ (1991) Opioid receptors and endogenous opioid peptides. Med Res Rev 11:357-374.

Simonds WF (1988) The molecular basis of opioid receptor function. Endocr Rev 9:200-212. 
Vanegas H, Barbaro NM, Fields HL (1984) Tail-flick related activity in medullospinal neurons. Brain Res 321:135-141.

Vaught JL (1991) What is the relative contribution of mu, delta, and kappa opioid receptors to antinociception and is there cross-tolerance? In: Towards a new pharmacotherapy of pain (Basbaum AI, Besson JL, eds), pp 121-136. Chichester: Wiley.

Williams FG, Beitz AJ (1990) Ultrastructural morphometric analysis of enkephalin-immunoreactive terminals in the ventrocaudal periaqueductal gray: analysis of their relationship to periaqueductal grayraphe magnus projection neurons. Neuroscience 38:381-94.

Williams RG, Dockray GJ (1983) Distribution of enkephalin-related peptides in rat brain: immunohistochemical studies using antisera to met-enkephalin and met-enkephalin $\mathrm{Arg}^{6} \mathrm{Phe}^{7}$. Neuroscience 9:563586. 